\title{
Tumor suppressor miR-149-5p is associated with cellular migration, proliferation and apoptosis in renal cell carcinoma
}

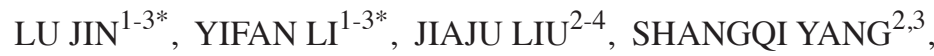 \\ YAOTING GUI $^{2}$, XIANGMING MAO ${ }^{2,3}$, GUOHUI NIE ${ }^{5}$ and YONGQING LAI ${ }^{2,3}$ \\ ${ }^{1}$ The Second Clinical College, Anhui Medical University, Hefei, Anhui 230032; \\ ${ }^{2}$ Guangdong and Shenzhen Key Laboratory of Male Reproductive Medicine and Genetics; \\ ${ }^{3}$ Department of Urology, Peking University Shenzhen Hospital, Shenzhen, Guangdong 518036; \\ ${ }^{4}$ Department of Clinical Medicine, Shantou University Medical College, Shantou, Guangdong 515041; \\ ${ }^{5}$ Department of Otolaryngology, Peking University Shenzhen Hospital, Shenzhen, Guangdong 518036, P.R. China
}

Received June 22, 2015; Accepted April 20, 2016

DOI: $10.3892 / \mathrm{mmr} .2016 .5205$

\begin{abstract}
Several studies have recently explored the role of microRNAs (miRNAs, miRs) in the tumorigenesis of various types of cancer. miRNAs have been reported to be involved in numerous cell processes, including cell apoptosis, proliferation and migration, thus suggesting that miRNAs may have an important role in cancer progression. Downregulation of miR-149-5p has been detected in RCC tissues by microarray profiling; however, its expression and function in RCC has yet to be elucidated. In the present study, reverse transcription-quantitative polymerase chain reaction was performed to detect the expression levels of miR-149-5p in RCC tissues and paired normal tissues. In order to determine whether miR-149-5p was able to regulate cell proliferation, apoptosis or migration, 3-(4,5-dimethylthiazol-2-yl)-2,5-diphenyltetrazolium bromide, flow cytometric and wound healing assays were conducted. The results demonstrated that miR-149-5p was significantly downregulated in RCC tissues compared with in normal tissues $(\mathrm{P}<0.05)$. The restoration of miR-149-5p expression using synthetic mimics suppressed cell proliferation and migration, and promoted cell apoptosis. These results indicated that miR-149-5p may act as a tumor suppressor in RCC. The present study is the first, to the best of our knowledge, to identify miR-149-5p as a tumor suppressor in RCC. Future studies will be focused on the potential role of miR-149-5p as a biomarker for the early detection and prognostic prediction of $\mathrm{RCC}$, and as a therapeutic target in RCC. In addition, further
\end{abstract}

Correspondence to: Professor Yongqing Lai, Department of Urology, Peking University Shenzhen Hospital, 1120 Lianhua Road, Shenzhen, Guangdong 518036, P.R. China

E-mail: yqlord@163.com

*Contributed equally

Key words: microRNA, microRNA-149-5p, renal cell carcinoma, tumor suppressor exploration regarding the pathways underlying the effects of miR-149-5p in RCC is required.

\section{Introduction}

MicroRNAs (miRNAs, miRs) are short non-coding, single-stranded RNAs $\sim 22$ nucleotides in length $(1,2)$, which were initially identified as developmental mediators in Caenorhabditis elegans (3). Previous studies have reported that miRNAs have an important role in the regulation of gene expression (4-6), and may be dysregulated in numerous disorders, including metabolic diseases, infectious diseases and cancer $(7,8)$. A substantial amount of evidence has suggested that miRNAs are aberrantly expressed in various types of human cancer, and previous studies have reported that miRNAs are implicated in tumor progression, including cell proliferation, migration, invasion and apoptosis (9-11). Dysregulation of miR-149-5p (also known as miR-149) has been reported to be associated with certain types of cancer, including nasopharyngeal carcinoma, colorectal cancer (CRC) and lung cancer (12-14). Furthermore, miR-149-5p has been revealed to be dysregulated in other diseases, including osteoarthritis and geriatric coronary artery disease $(15,16)$.

Renal cell carcinoma (RCC) is the most common type of kidney cancer, which accounts for 3-5\% of all malignant tumors $(17,18)$. In addition, RCC has the highest rate of recurrence and mortality among urological malignances (7). Approximately $50 \%$ of patients with RCC suffer relapse and metastasis following curative surgical resection (17). In addition, RCC is highly resistant to chemotherapy and radiotherapy (19). The approval of several targeted therapies has led to an improvement in the survival rate of some patients; however, advanced and metastatic RCC remains difficult to treat (20). Therefore, it is important to determine the molecular mechanisms underlying RCC and to identify a novel biomarker of RCC.

$\mathrm{miR}-149-5 \mathrm{p}$ has been reported to be dysregulated in various types of cancer, including nasopharyngeal carcinoma, CRC and lung cancer (12-14). However, the expression and function of miR-149-5p in RCC remains to be elucidated. The present 
study is the first to explore the possible role of miR-149-5p in the oncogenesis of RCC.

\section{Materials and methods}

Sample collection. A total of 32 paired RCC tissues and adjacent normal renal tissues were collected from Peking University Shenzhen Hospital (Shenzhen, China). Written informed consent was obtained from all patients. Collection and usage of the samples was reviewed and approved by the Ethics Committees of Peking University Shenzhen Hospital. Once the tissues were dissected they were immersed in RNAlater (Qiagen $\mathrm{GmbH}$, Hilden, Germany) for $30 \mathrm{~min}$, and were then stored at $-80^{\circ} \mathrm{C}$ until further use. The collected adjacent normal tissues were $2 \mathrm{~cm}$ away from visible RCC lesions. The collected tissues were reviewed and classified following hematoxylin and eosin staining. The clinical and pathological characteristics of the patients are presented in Table I. The ages of the patients varied between 25 and 70 years, and the mean age was 50 years old.

RNA extraction, $c D N A$ synthesis and quantitative polymerase chain reaction $(q P C R)$. Total RNA was extracted from the samples using TRIzol ${ }^{\circledR}$ reagent (Invitrogen; Thermo Fisher Scientific, Inc., Waltham, MA, USA) and was purified with the RNeasy Maxi kit (Qiagen $\mathrm{GmbH}$ ) according to the manufacturer's protocol. RNA concentration was measured using a NanoDrop 2000/2000c (NanoDrop Technologies; Thermo Fisher Scientific, Inc., Pittsburgh, PA, USA), and RNA samples with 260/280 ratios of 1.8-2.0 were used for further experiments. Reverse transcription (RT)-qPCR was performed to detect the expression levels of miR-149-5p in the samples. To obtain cDNA $1 \mu \mathrm{g}$ total RNA from each sample underwent RT using the miScript Reverse Transcription kit (Qiagen $\mathrm{GmbH}$ ) according to the manufacturer's protocol. qPCR was performed, in order to quantify the expression levels of miR-149-5p, using miScript SYBR ${ }^{\circledR}$ Green PCR kit (Qiagen $\mathrm{GmbH}$ ) on the Roche Lightcycler 480 Real-Time PCR system (Roche Diagnostics, Basel, Switzerland) according to the manufacturer's protocol. PCR reactions $(20 \mu \mathrm{l})$ contained $1 \mu \mathrm{l}$ cDNA template, $1 \mu$ l specific microRNA primer (Invitrogen; Thermo Fisher Scientific, Inc.), $2 \mu 1$ 10X miScript Universal Primer, $10 \mu \mathrm{l}$ 2X QuantiTect SYBR Green PCR Master Mix and RNase-free water. PCR was performed at $95^{\circ} \mathrm{C}$ for $30 \mathrm{sec}, 40$ cycles of $95^{\circ} \mathrm{C}$ for $5 \mathrm{sec}, 60^{\circ} \mathrm{C}$ for $30 \mathrm{sec}$ and $72^{\circ} \mathrm{C}$ for $30 \mathrm{sec}$, followed by incubation at $72^{\circ} \mathrm{C}$ for $15 \mathrm{~min}$. U6 was used as an internal control. The primer sequences were as follows: MiR-149-5p, forward 5'-TCTGGCTCCGTGTCT TCACTCCC-3', reverse primer was provided by the miScript SYBR $^{\circledR}$ Green PCR kit; and U6, forward 5'-CTCGCTTCG GCAGCACA-3' and reverse 5'-ACGCTTCACGAATTT GCGT-3'. The expression levels of miR-149-5p were analyzed using the $\Delta \Delta \mathrm{Cq}$ method (21).

Cell culture and transfection. The 786-O and ACHN human RCC cell lines were used in the present study (American Type Culture Collection, Manassas, VA, USA). The cells were cultured in Dulbecco's modified Eagle's medium (Gibco; Thermo Fisher Scientific, Inc., Waltham, MA, USA) supplemented with $10 \%$ fetal bovine serum (Gibco; Thermo
Table I. Clinicopathological features of patients with RCC.

\begin{tabular}{lc}
\hline Characteristic & Number of cases \\
\hline Mean age, range (years) & $50(25-70)$ \\
Gender & \\
Male/female & $20 / 12$ \\
Histological type & \\
Clear cell/papillary & $28 / 4$ \\
pT-stage & \\
T1/T2/T3+T4 & $18 / 12 / 2$ \\
Fuhrman grade & \\
I/II/III/IV & $9 / 16 / 5 / 2$ \\
AJCC clinical stages & \\
I/II/III+IV & $18 / 12 / 2$
\end{tabular}

pT, primary tumor; AJCC, American Joint Committee on Cancer.

Fisher Scientific, Inc.), $1 \%$ penicillin and streptomycin, and $1 \%$ glutamine at $37^{\circ} \mathrm{C}$ in a humidified incubator containing $5 \% \mathrm{CO}_{2}$. miR-149-5p expression was upregulated in these cells following transfection with synthesized miR-149-5p mimics (Shanghai GenePharma Co., Ltd., Shanghai, China) using Lipofectamine 2000 (Invitrogen; Thermo Fisher Scientific, Inc.), which was mixed with Opti-MEM ${ }^{\circledR}$ I Reduced Serum Medium (Gibco; Thermo Fisher Scientific, Inc.) according to the manufacturer's protocol. Fluorescence microscopy (DMIRB; Leica Microsystems, Inc., Buffalo Grove, IL, USA). and RT-qPCR were performed to observe the transfection efficiency and the alterations to miR-149-5p expression. The sequence of the miR-149-5p mimics is 5'-UCUGGCUCCGUG UCUUCACUCCC-3'.

Wound healing cell migration assay. The wound healing assay was performed to assess the migratory ability of 786-O and ACHN cells in vitro. Cells $\left(\sim 3 \times 10^{5}\right)$ were seeded into every well of a 12-well plate, and after $24 \mathrm{~h}$ the cells were transfected with 100 pmol miR-149-5p mimics or negative control mimics (5'-UUCUCCGAACGUGUCACGUTT-3'; Shanghai GenePharma Co., Ltd.) using Lipofectamine ${ }^{\circledR} 2000$. A total of $6 \mathrm{~h}$ post-transfection, a vertical horizontal line was scratched into the cell layer using a sterile $200 \mu \mathrm{l}$ pipette tip. To remove the floating cells, the plates were rinsed with phosphate-buffered saline and were then cultured at $37^{\circ} \mathrm{C}$ in a humidified chamber containing $5 \% \mathrm{CO}_{2}$. A digital camera system (DP Controller and DP manager; Olympus Corporation, Tokyo, Japan). was used to capture images of the scratches at 0 and $24 \mathrm{~h}$ after generation of the scratch. The experiments were performed in triplicate and were repeated at least three times.

MTT cell proliferation assay. A 3-(4,5-dimethylthiazol-2-yl)-2,5-diphenyltetrazolium bromide (MTT) assay was performed to assess the proliferative ability of 786-O and ACHN cells in vitro. Cells $\left(\sim 5 \times 10^{3}\right)$ were seeded into each well of a 96-well plate and were then transfected with 5 pmol miR-149-5p mimics or negative control mimics. A total of $20 \mu \mathrm{l}$ MTT (5 mg/ml; Sigma-Aldrich, St Louis, MO, USA) was 

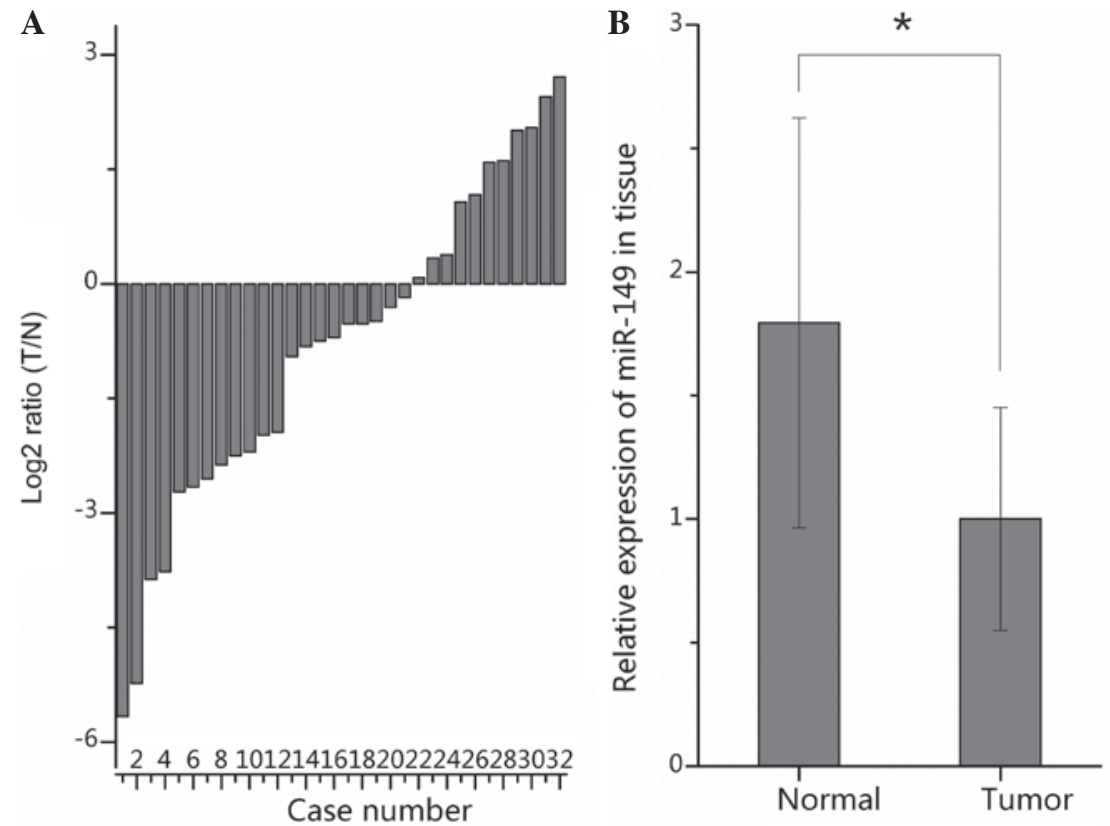

Figure 1. MicroRNA (miR)-149-5p is significantly downregulated in renal cell carcinoma (RCC) tissues compared with in normal tissues. (A) Ratios of miR-149-5p expression in 32 paired tissues [ $\log _{2}$ Ratio $\left.(\mathrm{T} / \mathrm{N})\right]$. (B) Relative expression levels of miR-149-5p in RCC and normal tissues ("P $\left.<0.05\right)$. Data are presented as the mean \pm standard error. T, tumor; N. normal.

added to each well at $0,24,48$ and $72 \mathrm{~h}$ post-transfection, and the 96 -well plate was incubated at $37^{\circ} \mathrm{C}$ in a humidified incubator containing $5 \% \mathrm{CO}_{2}$ for $6 \mathrm{~h}$. Subsequently, the medium was replaced with $150 \mu 1$ dimethylsulfoxide [Sigma-Aldrich (Shanghai) Trading Co., Ltd., Shanghai, China]. The 96-well plate was then agitated for $30 \mathrm{~min}$ at room temperature and the optical density of each well was measured using an enzyme-linked immunosorbent assay microplate reader (model 680; Bio-Rad Laboratories, Inc., Hercules, CA, USA) at a wavelength of $490 \mathrm{~nm}$.

Flow cytometric apoptosis assay. The apoptotic rates of 786-O and ACHN cells were measured in vitro by flow cytometry. Cells $\left(\sim 3 \times 10^{5}\right)$ were seeded into each well of a 6 -well plate and were then transfected with 200 pmol miR-149-5p mimics or negative control mimics. A total of $48 \mathrm{~h}$ post-transfection the cells were harvested and washed twice with cold PBS. Subsequently, the cells were resuspended in $100 \mu 11 \mathrm{X}$ binding buffer, and $5 \mu \mathrm{l}$ Annexin V-fluorescein isothiocyanate (FITC; Invitrogen; Thermo Fisher Scientific, Inc.) and $5 \mu \mathrm{l}$ propidium iodide (PI; Invitrogen; Thermo Fisher Scientific, Inc.) were added to each cell suspension. After staining for $15 \mathrm{~min}$ at room temperature in the dark, $400 \mu 1$ binding buffer was added to each tube. A Navios flow cytometer (Beckman, CA, USA) was used to analyze the rate of apoptosis.

Statistical analysis. Data are presented as the mean \pm standard error. Paired t-test was used to compare the expression levels of miR-149-5p between the matched tumor and normal tissues. Student's t-test was used to analyze assays characterizing cell phenotypes. $\chi^{2}$ test was performed to explore the correlations between pathological characteristics and the expression levels of miR-149-5p in tumor tissues. No correlations were demonstrated between pathological characteristics and the expression levels of miR-149-5p in tumor tissues (results not shown). All

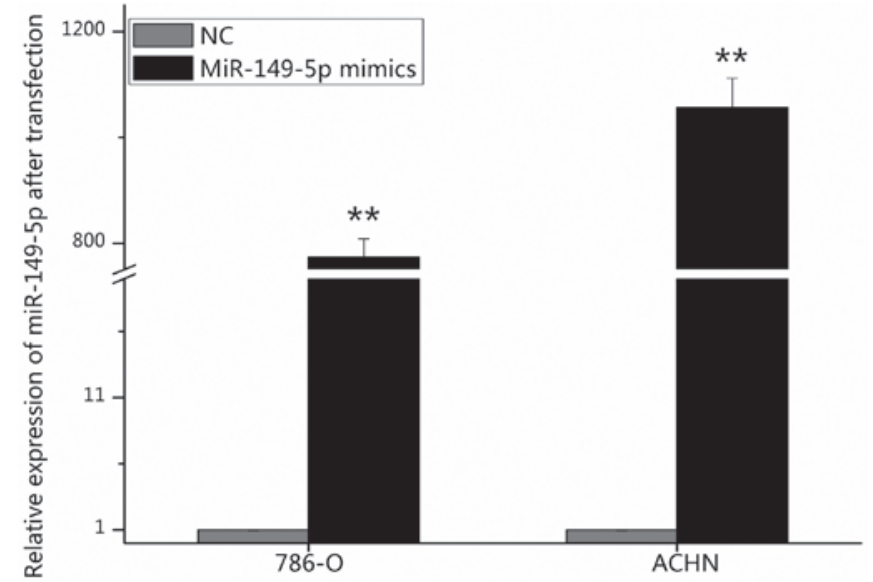

Figure 2. Relative expression levels of microRNA (miR)-149-5p post-transfection $\left({ }^{* *} \mathrm{P}<0.01\right)$. Data are presented as the mean \pm standard error. $\mathrm{NC}$, negative control.

statistical analyses were carried out using SPSS 19.0 statistical software package (IBM SPSS, Armonk, NY, USA). P $<0.05$ was considered to indicate a statistically significant difference.

\section{Results}

miR-149-5p is downregulated in RCC tissues compared with in adjacent normal tissues. A total of 32 paired RCC and adjacent normal tissues were used to detect the expression levels of miR-149-5p by qPCR. The ratios of miR-149-5p expression in the 32 paired tissues $\left[\log _{2}\right.$ Ratio $\left.(\mathrm{T} / \mathrm{N})\right]$ are presented in Fig. 1A, which indicated that miR-149-5p was downregulated in 21 RCC tissues. The expression levels of miR-149-5p were significantly lower in RCC tissues compared with in paired normal tissues $(\mathrm{P}=0.034$; Fig. $1 \mathrm{~B})$. These results suggest that 

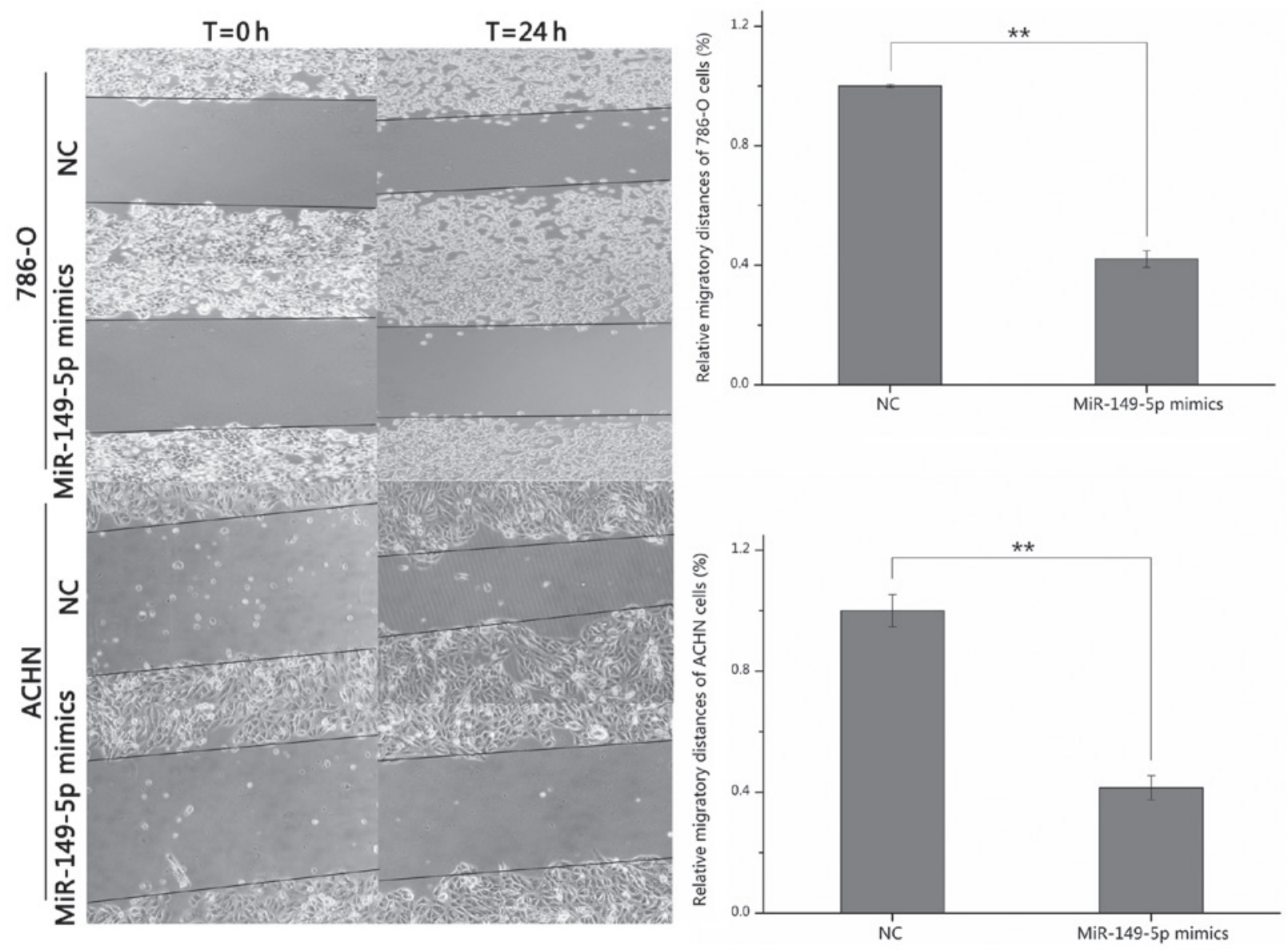

Figure 3. Images of the wounds at 0 and $24 \mathrm{~h}$ post-transfection $\left({ }^{* *} \mathrm{P}<0.01\right)$. Magnification, $\mathrm{x} 100$. Data are presented as the mean \pm standard error. miR, microRNA; NC, negative control; T, time.

miR-149-5p may function as a tumor suppressor in RCC; however, the mechanism underlying the effects of miR-149-5p in RCC remains unclear.

Validation of cell transfection efficiency. qPCR was performed to determine the transfection efficiency of miR-149-5p mimics compared with negative control mimics. The expression levels of miR-149-5p were 773.74 times higher in 786-O cells $(\mathrm{P}=0.000324)$ and $1,056.45$ times higher in ACHN cells $(\mathrm{P}=0.000605)$ transfected with miR-149-5p mimics, compared with in the negative control group (Fig. 2).

miR-149-5p mimics inhibit 786-O and ACHN cell migration. To explore the function of miR-149-5p in cell migration, a wound healing assay was conducted. Images of the wounds were captured at 0 and $24 \mathrm{~h}$ post-transfection using a digital camera system (Fig. 3). The wound widths of the cells transfected with miR-149-5p mimics were wider compared with the cells transfected with the negative control mimics. A total of $24 \mathrm{~h}$ post-transfection the distance of migration in the miR-149-5p mimics group was decreased by $57.88 \%$ in $786-\mathrm{O}$ cells and $58.54 \%$ in ACHN cells compared with the negative control group $(\mathrm{P}<0.01)$. These results indicate that the upregulation of miR-149-5p may suppress RCC cell migration.

miR-149-5p mimics inhibit 786-O and ACHN cell proliferation. To determine whether miR-149-5p was able to affect RCC cell proliferation, an MTT assay was conducted. Post-transfection with miR-149-5p mimics the proliferation of 786-O cells was decreased by $7.43 \%(24 \mathrm{~h} ; \mathrm{P}=0.0258), 11.90 \%$ (48 h; P=0.00801) and $19.46 \%(72 \mathrm{~h} ; \mathrm{P}=0.00288)$ compared with the negative control group (Fig. 4A). In the ACHN cells, proliferation was decreased by $6.93 \%$ ( $24 \mathrm{~h} ; \mathrm{P}=0.0347), 17.29 \%$ (48 h; $\mathrm{P}=0.00178$ ) and $21.20 \%$ (72 h; $\mathrm{P}=0.000278$ ) (Fig. 4B). These results suggest that upregulation of miR-149-5p may inhibit RCC cell proliferation.

miR-149-5p mimics promote 786-O and ACHN cell apoptosis. To explore the role of miR-149-5p in RCC cell apoptosis, a flow cytometric analysis was conducted. The average early apoptotic rate of negative control-transfected 786-O cells was $1.89 \%$, which increased to $17.15 \%$ in cells transfected with miR-149-5p mimics ( $\mathrm{P}=0.00112$; Fig. 5A). Furthermore, the average apoptotic rate of ACHN cells transfected with miR-149-5p mimics or negative control mimics was 21.30 and $3.21 \%$, respectively ( $\mathrm{P}=0.00106$; Fig. $5 \mathrm{~B})$. These results indicate that miR-149-5p may promote the apoptosis of RCC cells.

\section{Discussion}

The mechanism underlying oncogenesis and cancer development remains unclear, and various oncogenes and tumor suppressor genes have a role in the process of oncogenesis. The most familiar genes associated with RCC tumorigenesis 

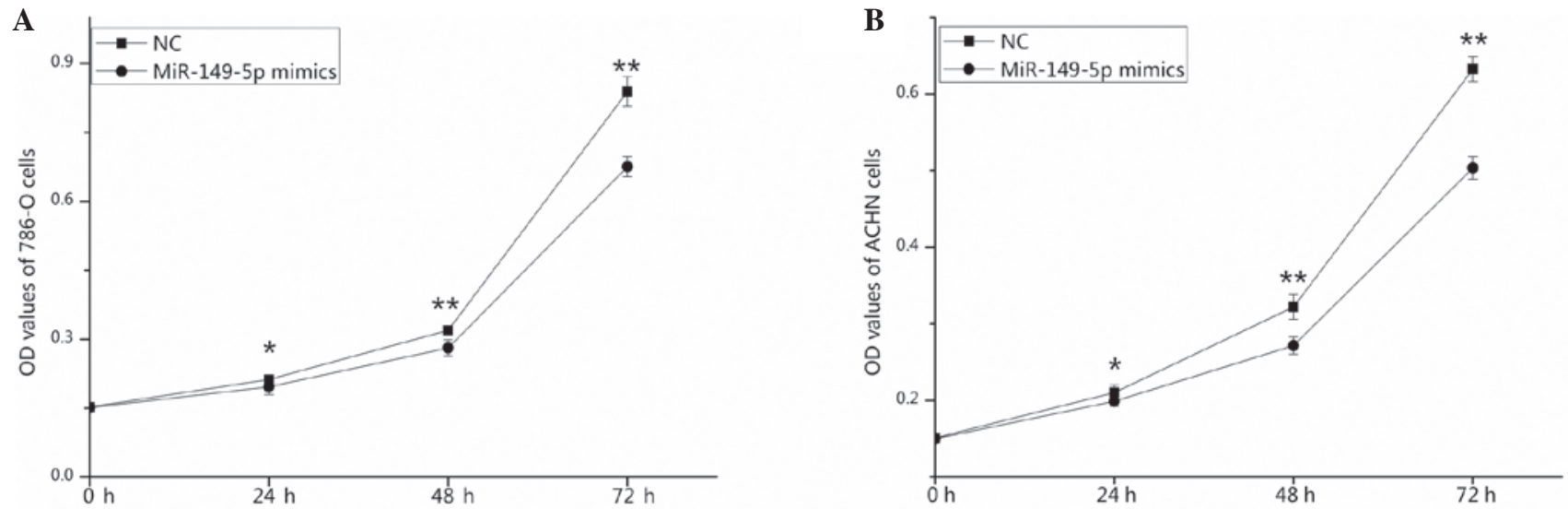

Figure 4. Results of a 3-(4,5-dimethylthiazol-2-yl)-2,5-diphenyltetrazolium bromide assay. (A) Optical density (OD) values of 786-O cells at $0,24,48$ and $72 \mathrm{~h}$ post-transfection. (B) OD values of ACHN cells at $0,24,48$ and $72 \mathrm{~h}$ post-transfection ${ }^{*} \mathrm{P}<0.05,{ }^{* * *} \mathrm{P}<0.01$ vs. NC. Data are presented as the mean \pm standard error. miR, microRNA; NC, negative control.

A

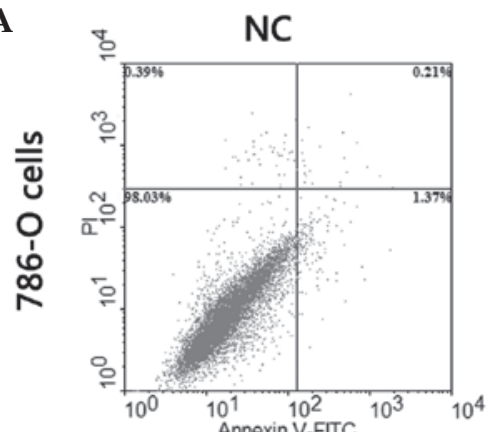

$\mathbf{B}$

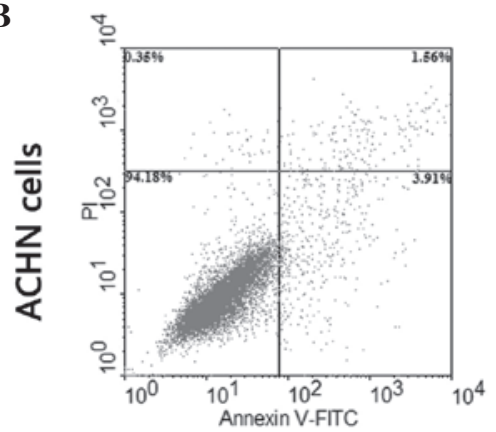

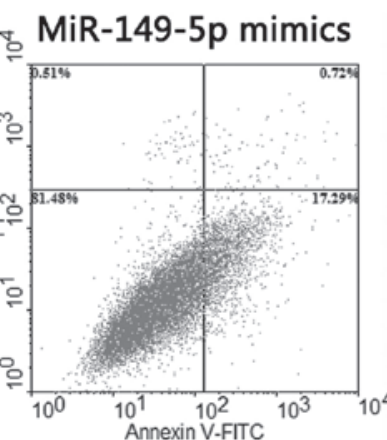

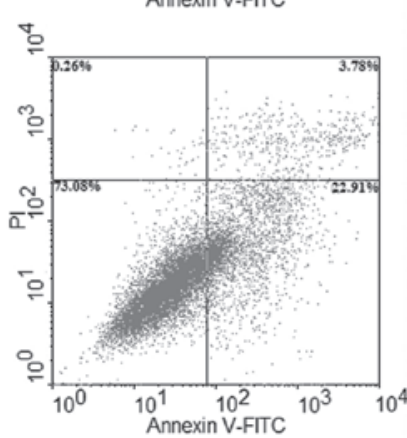

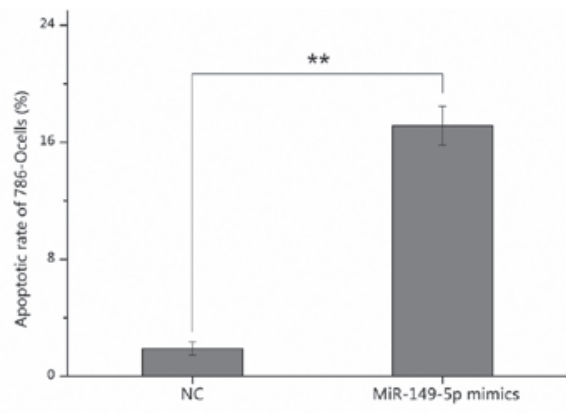

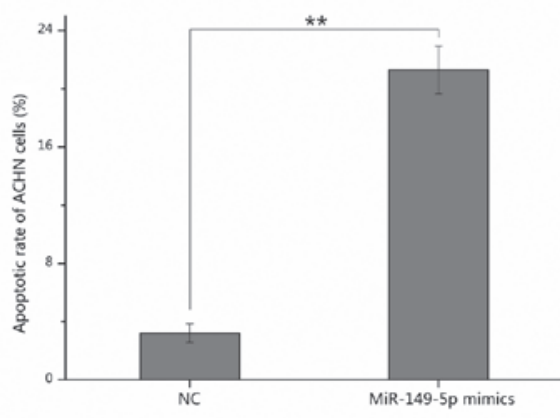

Figure 5. Early apoptotic rate of cells post-transfection. Apoptotic rate of (A) 786-O and (B) ACHN cells transfected with negative control (NC) or microRNA $(\mathrm{miR})-149-5 \mathrm{p}$ mimics. ("* $\mathrm{P}<0.01)$. Data are presented as the mean \pm standard error. FITC, fluorescein isothiocyanate; PI, propidium iodide.

are von Hippel-Lindau (VHL), hypoxia-inducible factor (HIF), vascular endothelial growth factor (VEGF) and the mammalian target of rapamycin (mTOR) pathway. At present, various miRNAs have been revealed to be associated with the regulation of gene expression, and it is estimated that $\sim 50 \%$ of human genes are the target of miRNAs $(7,22)$. Notably, VHL, HIF, VEGF and mTOR are regulated by miRNAs, thus suggesting that miRNAs may have a crucial role in RCC tumorigenesis and development $(23,24)$.

miR-149-5p has been reported to be dysregulated in various types of cancer, including non-small-cell lung cancer (NSCLC) (25), CRC (26) and astrocytoma (27). However, the expression levels of miR-149-5p in RCC have not yet been validated by qPCR. A recent microarray study between RCC and normal tissues indicated that miR-149 was downregulated, and demonstrated that the possible mRNA targets of miR-149 in clear cell RCC were lysyl oxidase (LOX), voltage-gated potassium channel subunit beta-1 and calcium-activated potassium channel subunit alpha-1 (28). Therefore, in the present study, qPCR was performed to quantify the expression levels of miR-149-5p in RCC tissues and paired adjacent normal tissues. In addition, the present study aimed to determine whether miR-149-5p could affect RCC cell proliferation, migration or apoptosis, as determined by MTT, wound healing and flow cytometric assays, respectively. The results revealed that miR-149-5p was downregulated in RCC tissues compared with in adjacent normal tissues. Furthermore, overexpression of miR-149-5p with miR-149-5p mimics significantly inhibited RCC cell (786-O and $\mathrm{ACHN}$ cells) proliferation and migration, and promoted RCC cell apoptosis. These results suggested that miR-149-5p may have a role as a tumor suppressor in RCC. 
The mechanisms underlying how miR-149-5p affects cell progression remain unclear, and have been described differently in various types of cancer. For example, miR-149 was revealed to inhibit NSCLC cells epithelial-mesenchymal transition by targeting forkhead box M1 (25). In glioblastoma cells, miR-149 was able to increase chemosensitivity to temozolomide (27). Furthermore, the expression levels of miR-149 were gradually decreased in astrocytomas of different World Health Organization grades (27), thus indicating that miR-149 may be a biomarker of astrocytoma. In CRC, overexpression of miR-149 inhibited CRC cell growth and invasion by targeting specificity protein 1 (26). In addition, lower miR-149 expression was associated with a greater depth of invasion and reduced 5-year survival rate in CRC (26). These data revealed that miR-149 may have an important role in the tumorigenesis of CRC and may be used as a biomarker to predict prognosis. He et al (29) reported that miR-149 was downregulated in adriamycin-resistant human breast cancer cells, and was involved in chemoresistance by targeting GlcNAc $\mathrm{N}$-deacetylase/N-sulfotransferase-1. In gastric cancer, miR-149 was reported to inhibit proliferation and induce cell cycle arrest by targeting zinc finger and BTB domain containing 2 (30). These studies suggested that miR-149 is associated with the tumorigenesis or chemoresistance of cancer; however, the role of miR-149 in RCC remains unclear. Therefore, the present study performed MTT, wound healing and apoptosis assays, in order to explore the function of miR-149-5p in RCC cells. The results suggested that miR-149-5p functions as a tumor suppressor in RCC.

The association between miR-149 rs2292832 polymorphism and cancer risk has been explored in previous studies. Genetic polymorphisms within a miRNA sequence are thought to have a functional impact on how miRNAs function in tumors (31). Huang et al (32) reported that the CC genotype of miR-149 contributes to the progression and development, rather than the initiation, of nasopharyngeal carcinoma. Furthermore, the miR-149 rs2292832 polymorphism may be involved in the susceptibility and local progression of papillary thyroid cancer in Chinese patients (33). However, studies failed to describe the predictive ability of the polymorphism when lung cancers or breast cancers were examined $(34,35)$. As well as in cancer, miR-149 rs71428439 polymorphism may affect miR-149 maturation, and this polymorphism may contribute to the risk of myocardial infarction via the miR-149-Puma axis (36). Nevertheless, the associations between miR-149 polymorphism and $\mathrm{RCC}$ risk have yet to be elucidated, and the mechanisms by which miR-149 regulates RCC biological processes remain ill-defined. Therefore, knowledge regarding the mechanisms underlying RCC tumorigenesis and development may improve by researching the pathways or target genes of miR-149 in RCC.

In conclusion, the present study detected the expression levels of miR-149-5p in RCC and paired adjacent normal tissues. miR-149-5p was downregulated in RCC, and cellular processes were altered following the upregulation of miR-149-5p, thus suggesting that miR-149-5p acts as a tumor suppressor in RCC. Further studies will be focused on the potential role of miR-149-5p as a biomarker for the early detection and prognostic prediction of RCC, and as a therapeutic target in RCC. In addition, further exploration regarding the pathways underlying the effects of miR-149-5p in RCC is required.

\section{Acknowledgements}

The present study was supported by the National Natural Science Foundation of China (grant. no. 81101922), Science and Technology Development Fund Project of Shenzhen (grant nos. JCYJ20130402114702124 and JCYJ20150403091443329) and the fund of Guangdong Key Medical Subject.

\section{References}

1. Coskun M, Bjerrum JT, Seidelin JB, Troelsen JT, Olsen J and Nielsen $\mathrm{OH}$ : miR-20b, miR-98, miR-125b-1*, and let-7e* as new potential diagnostic biomarkers in ulcerative colitis. World J Gastroenterol 19: 4289-4299, 2013.

2. Jeon YJ, Kim OJ, Kim SY, Oh SH, Oh D, Kim OJ, Shin BS and Kim NK: Association of the miR-146a, miR-149, miR-196a2, and miR-499 polymorphisms with ischemic stroke and silent brain infarction risk. Arterioscler Thromb Vasc Biol 33: 420-430, 2013.

3. Deng S, Zhang Y, Xu C and Ma D: MicroRNA-125b-2 overexpression represses ectodermal differentiation of mouse embryonic stem cells. Int J Mol Med 36: 355-362, 2015.

4. Li J, Liang H, Bai M, Ning T, Wang C, Fan Q, Wang Y, Fu Z, Wang N, Liu R, et al: miR-135b promotes cancer progression by targeting transforming growth factor beta receptor II (TGFBR2) in colorectal cancer. PloS One 10: e0130194, 2015.

5. Xu L, Zhou X, Qiu MT, Yin R, Wu YQ and Xu L: Lack of association between hsa-miR-149 rs2292832 polymorphism and cancer risk: A meta-analysis of 12 studies. PloS One 8: e73762, 2013.

6. Zhang MW, Jin MJ, Yu YX, Zhang SC, Liu B, Jiang X, Pan YF, Li QI, Ma SY and Chen K: Associations of lifestyle-related factors, hsa-miR-149 and hsa-miR-605 gene polymorphisms with gastrointestinal cancer risk. Mol Carcinog 51 (Suppl 1): E21-E31, 2012.

7. Chen D, Li Y, Yu Z, Li Y, Su Z, Ni L, Yang S, Gui Y and Lai Y: Downregulated microRNA-510-5p acts as a tumor suppressor in renal cell carcinoma. Mol Med Rep 12: 3061-3066, 2015.

8. Tu HF, Liu CJ, Chang CL, Wang PW, Kao SY, Yang CC, Yu EH, Lin SC and Chang KW: The association between genetic polymorphism and the processing efficiency of miR-149 affects the prognosis of patients with head and neck squamous cell carcinoma. PloS One 7: e51606, 2012.

9. Matsushita R, Seki N, Chiyomaru T, Inoguchi S, Ishihara T, Goto Y, Nishikawa R, Mataki H, Tatarano S, Itesako T, et al: Tumour-suppressive microRNA-144-5p directly targets CCNE1/2 as potential prognostic markers in bladder cancer. Br J Cancer 113: 282-289, 2015.

10. Tsai MM, Wang CS, Tsai CY, Chen CY, Chi HC, Tseng YH, Chung PJ, Lin YH, Chung IH, Chen CY and Lin KH: MicroRNA-196a/-196b promote cell metastasis via negative regulation of radixin in human gastric cancer. Cancer Lett 351: 222-231, 2014.

11. Tian X, WeiZ, Wang J,Liu P, Qin Y andZhong M: MicroRNA-429 inhibits the migration and invasion of colon cancer cells by targeting PAK6/cofilin signaling. Oncol Rep 34: 707-714, 2015.

12. Luo Z, Zhang L, Li Z, Jiang C, Dai Y, Liu X, Zheng Y, Yu H, Xiang J and Li G: miR-149 promotes epithelial-mesenchymal transition and invasion in nasopharyngeal carcinoma cells. Zhong Nan Da Xue Xue Bao Yi Xue Ban 36: 604-609, 2011.

13. Øster B, Linnet L, Christensen LL, Thorsen K, Ongen H, Dermitzakis ET, Sandoval J, Moran S, Esteller M, Hansen TF, et al: Non-CpG island promoter hypomethylation and miR-149 regulate the expression of SRPX 2 in colorectal cancer. Int J Cancer 132: 2303-2315, 2013

14. Vinci S, Gelmini S, Pratesi N, Conti S, Malentacchi F, Simi L, Pazzagli $M$ and Orlando C: Genetic variants in miR-146a, miR-149, miR-196a2, miR-499 and their influence on relative expression in lung cancers. Clin Chem Lab Med 49: 2073-2080, 2011.

15. Santini P, Politi L, Vedova PD, Scandurra R and Scotto d'Abusco A: The inflammatory circuitry of miR-149 as a pathological mechanism in osteoarthritis. Rheumatol Int 34: 711-716, 2014. 
16. Ali Sheikh MS, Xia K, Li F, Deng X, Salma U, Deng H, Wei Wei L, Yang TL and Peng J: Circulating miR-765 and miR-149: Potential noninvasive diagnostic biomarkers for geriatric coronary artery disease patients. Biomed Res Int 2015: 740301, 2015.

17. Yim NH, Jung YP, Kim A, Kim T and Ma JY: Induction of apoptotic cell death by betulin in multidrug-resistant human renal carcinoma cells. Oncol Rep 34: 1058-1064, 2015.

18. Siegel R, Naishadham D and Jemal A: Cancer statistics, 2013. CA Cancer J Clin 63: 11-30, 2013.

19. Hong MH, Kim HS, Kim C, Ahn JR, Chon HJ, Shin SJ, Ahn JB, Chung HC and Rha SY: Treatment outcomes of sunitinib treatment in advanced renal cell carcinoma patients: A single cancer center experience in Korea. Cancer Res Treat 41: 67-72, 2009.

20. Xiao W, Gao Z, Duan Y, Yuan W and Ke Y: Downregulation of miR-19a exhibits inhibitory effects on metastatic renal cell carcinoma by targeting PIK3CA and inactivating Notch signaling in vitro. Oncol Rep 34: 739-746, 2015

21. Livak KJ and Schmittgen TD: Analysis of relative gene expression data using real-time quantitative PCR and the 2(-Delta Delta C(T)) Method. Methods 25: 402-408, 2001.

22. Lu YC, Chang JT, Huang YC, Huang CC, Chen WH, Lee LY, Huang BS, Chen YJ, Li HF and Cheng AJ: Combined determination of circulating miR-196a and miR-196b levels produces high sensitivity and specificity for early detection of oral cancer. Clin Biochem 48: 115-121, 2015.

23. Chow TF, Mankaruos M, Scorilas A, Youssef Y, Girgis A, Mossad S, Metias S, Rofael Y, Honey RJ, Stewart R, et al: The miR-17-92 cluster is over expressed in and has an oncogenic effect on renal cell carcinoma. J Urol 183: 743-751, 2010.

24. Maher ER: Genomics and epigenomics of renal cell carcinoma Semin Cancer Biol 23: 10-17, 2013.

25. Ke Y,Zhao W, Xiong J and Cao R: miR-149 inhibits non-small-cell lung cancer cells EMT by targeting FOXM1. Biochem Res Int 2013: 506731, 2013.

26. Wang F, Ma YL, Zhang P, Shen TY, Shi CZ, Yang YZ, Moyer MP, Zhang HZ, Chen HQ, Liang Y and Qin HL: SP1 mediates the link between methylation of the tumour suppressor miR-149 and outcome in colorectal cancer. J Pathol 229: 12-24, 2013.
27. She X, Yu Z, Cui Y, Lei Q, Wang Z, Xu G, Xiang J, Wu M and Li G: miR-128 and miR-149 enhance the chemosensitivity of temozolomide by Rap1B-mediated cytoskeletal remodeling in glioblastoma. Oncol Rep 32: 957-964, 2014

28. Liu H, Brannon AR, Reddy AR, Alexe G, Seiler MW, Arreola A, Oza JH, Yao M, Juan D, Liou LS, et al: Identifying mRNA targets of microRNA dysregulated in cancer: With application to clear cell renal cell carcinoma. BMC Syst Biol 4: 51, 2010.

29. He DX, Gu XT, Li YR, Jiang L, Jin J and Ma X: Methylationregulated miR-149 modulates chemoresistance by targeting GlcNAc N-deacetylase/N-sulfotransferase-1 in human breast cancer. FEBS J 281: 4718-4730, 2014.

30. Wang Y, Zheng X, Zhang Z, Zhou J, Zhao G, Yang J, Xia L, Wang R, Cai X, Hu H, et al: MicroRNA-149 inhibits proliferation and cell cycle progression through the targeting of ZBTB2 in human gastric cancer. PloS One 7: e41693, 2012.

31. Hu Z, Chen J, Tian T, Zhou X, Gu H, Xu L, Zeng Y, Miao R, Jin G, $\mathrm{Ma} \mathrm{H}$, et al: Genetic variants of miRNA sequences and non-small cell lung cancer survival. J Clin Invest 118: 2600-2608, 2008.

32. Huang GL, Lu Y, Pu XX, He YX, Chen ML, Li YZ, Tang SY, Che $\mathrm{H}$ and $\mathrm{He} \mathrm{Z}$ : Association study between miR-149 gene polymorphism and nasopharyngeal carcinoma. Biomed Rep 1: 599-603, 2013

33. Wei WJ, Lu ZW, Li DS, Wang Y, Zhu YX, Wang ZY, Wu Y, Wang YL and Ji QH: Association of the miR-149 Rs2292832 polymorphism with papillary thyroid cancer risk and clinicopathologic characteristics in a Chinese population. Int J Mol Sci 15: 20968-20981, 2014.

34. Xu L and Tang $\mathrm{W}$ : The associations of nucleotide polymorphisms in mir-196a2, mir-146a, mir-149 with lung cancer risk. Cancer Biomark 15: 57-63, 2015.

35. Zhang M, Jin M, Yu Y, Zhang S, Wu Y, Liu H, Liu H, Chen B, $\mathrm{Li} \mathrm{Q}$, Ma X and Chen K: Associations of miRNA polymorphisms and female physiological characteristics with breast cancer risk in Chinese population. Eur J Cancer Care (Engl) 21: 274-280, 2012.

36. Ding SL, Wang JX, Jiao JQ, Tu X, Wang Q, Liu F, Li Q, Gao J, Zhou QY, Gu DF and Li PF: A pre-microRNA-149 (miR-149) genetic variation affects miR-149 maturation and its ability to regulate the Puma protein in apoptosis. J Biol Chem 288: 26865-26877, 2013. 